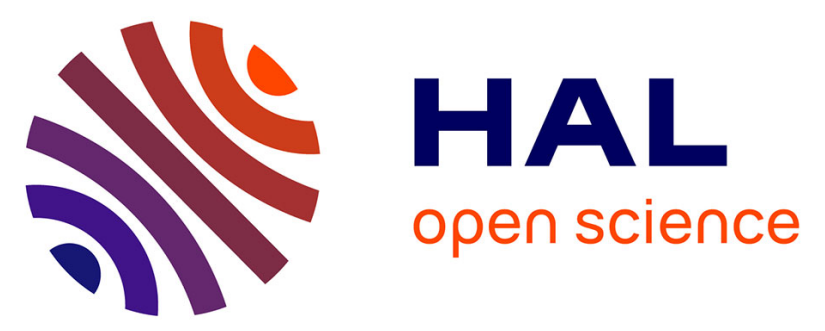

\title{
Osmotic pressures of lysozyme solutions from gas-like to crystal states
}

C. Pasquier, Sylvie Beaufils, Antoine Bouchoux, S. Rigault, B. Cabane, M. Lund, Valérie Lechevalier-Datin, Cécile Le Floch-Fouéré, M. Pasco, G. Paboeuf, et al.

\section{To cite this version:}

C. Pasquier, Sylvie Beaufils, Antoine Bouchoux, S. Rigault, B. Cabane, et al.. Osmotic pressures of lysozyme solutions from gas-like to crystal states. Physical Chemistry Chemical Physics, 2016, 18 (41), pp.28458-28465. 10.1039/c6cp03867k . hal-01397941

\section{HAL Id: hal-01397941 \\ https://hal-univ-rennes1.archives-ouvertes.fr/hal-01397941}

Submitted on 2 Oct 2018

HAL is a multi-disciplinary open access archive for the deposit and dissemination of scientific research documents, whether they are published or not. The documents may come from teaching and research institutions in France or abroad, or from public or private research centers.
L'archive ouverte pluridisciplinaire HAL, est destinée au dépôt et à la diffusion de documents scientifiques de niveau recherche, publiés ou non, émanant des établissements d'enseignement et de recherche français ou étrangers, des laboratoires publics ou privés. 


\title{
Osmotic pressures of lysozyme solutions from gas-like to crystal state
}

\author{
Coralie Pasquier, ${ }^{\mathrm{a}, \mathrm{b}}$, Sylvie Beaufils ${ }^{\mathrm{b}}$, Antoine Bouchoux ${ }^{\mathrm{a}, \mathrm{c}}$, Sophie \\ Rigault $^{\mathrm{a}}$, Bernard Cabane ${ }^{\mathrm{d}}$, Mikael Lund ${ }^{\mathrm{e}}$, Valérie Lechevaliera ${ }^{\mathrm{a}}$, Cécile \\ Le Floch-Fouéréa ${ }^{\mathrm{a}}$, Maryvonne Pasco ${ }^{\mathrm{a}}$, Gilles Pabœuf ${ }^{\mathrm{b}}$, Javier Pérez ${ }^{\mathrm{f}}$, \\ and Stéphane Pezennec*1

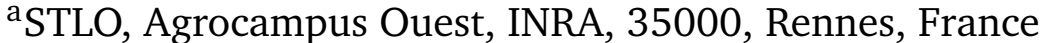 \\ ${ }^{b}$ Institut de Physique de Rennes, UMR6251 CNRS-Université de \\ Rennes 1, F-35042 Rennes, France \\ 'LISBP, UMR 5504/792 INRA-CNRS-INSA, 135 avenue de Rangueil, \\ F-31077 Toulouse CEDEX 04, France \\ ${ }^{\mathrm{d}}$ Laboratoire CBI, CNRS UMR 8231, Université Pierre et Marie Curie, \\ Université Diderot, ESPCI, 10 rue Vauquelin, F-75231, \\ Paris CEDEX 05, France \\ e Department of Theoretical Chemistry, Lund University, P.O. Box 124, \\ SE-22100 Lund, Sweden \\ ${ }^{\text {f}}$ Synchrotron SOLEIL, F-91192 Gif-sur-Yvette, France
}

DOI:10.1039/C6CP03867K ${ }^{1}$

\begin{abstract}
We obtained osmotic pressure data of lysozyme solutions, describing their physical states over a wide concentration range, using osmotic
\end{abstract}

\footnotetext{
*Corresponding author, stephane.pezennec@inra.fr

${ }^{1}$ Electronic Supplementary Information (ESI) available: net charge of lysozyme as a function of pH (Fig. S1); reversibility of osmotic stress at $150 \mathrm{mM}$ and $35 \mathrm{mM}$ ionic strengths (Fig. S2 and S3); Fourier transform infrared spectroscopy and secondary structure of lysozyme, experimental procedure and results (Fig. S4); small-angle X-ray scattering, experimental procedure and results (Fig. S5); generalized van der Waals model (GVDW); fitting of the GVDW model with and without screening of electrosatic interactions by counterions (Fig. S6); impact of the value of the radius of the lysozyme model on the osmotic pressure predicted by the GVDW model (Fig. S7); references.
} 
stress for pressures between 0.05 bar and about 40 bar and volume fractions between 0.01 and 0.61 . The osmotic pressure $v s$. volume fraction data consist of a dilute, gas-phase regime, a transition regime with a high-compressibility plateau, and a concentrated regime where the system is nearly incompressible. The first two regimes are shifted towards higher protein volume fraction upon decrease in the strength or the range of electrostatic interactions. We describe this shift and the overall shape of the experimental data in these two regimes through a model accounting for a steric repulsion, a short-range van der Waals attraction and a screened electrostatic repulsion. The transition is caused by crystallization, as shown by small-angle X-ray scattering. We verified that our data points correspond to thermodynamic equilibria, thus that they consist in the reference experimental counterpart of a thermodynamic equation of state.

\section{Introduction}

Knowledge about the interactions in very concentrated solutions of proteins, namely up to a few hundred grams per liter, is of high relevance in various fields, such as the living cell physiology, food transformation (foams, powders, membrane filtration...), pharmacology and drug delivery, or diseases implying phase transition of proteins ${ }^{1-7}$. Predictive models, relying mostly on the knowledge originated from colloidal physics, have been proposed for the behavior of concentrated proteins ${ }^{8-10}$. However, they fail to catch the complexity and the variability of the protein molecules, related to the combination of their different levels of structure with the distinct physicochemical properties of the amino-acid residues.

Osmotic pressure measurements enable to probe protein-protein, protein-ion or protein-solvent interactions. Data about globular proteins have been established in the past ${ }^{11-14}$, however the highest concentrations that were obtained were never high enough to enable the system to go out of a dilute or semi-dilute range. In this work we report results obtained through osmotic stress ${ }^{15-23}$ as a concentration technique. This method makes it possible to control the osmotic pressure over a wide range of volume fractions (spanning from the dilute phase to phases where interactions play a prominent role, up to the solid phase) and to reach the same concentration state by different pathways, while keeping constant salt activity.

We study lysozyme, a globular protein that has been well characterized since its discovery in 1922. Numerous studies have been conducted on lysozyme, in particular its self-interaction characteristics when concentrated or submitted to changes in the physicochemical conditions $^{9,24-35}$. Specifically, lysozyme has been shown, as other non- 
protein colloids, to exhibit a combination of long-range repulsive, and short-range attractive interactions, which leads to the formation of equilibrium clusters ${ }^{24,25}$.

In the present work, we aim to bring answers to the following questions:

- Do the diagrams relating osmotic pressure $\Pi$ to volume fraction $\phi$ enable us to identify transitions of the system during concentration?

- If we tune the interactions, do the diagrams reflect the changes? Is it in a predictable way?

- What are the positions of the $(\phi, \Pi)$ lines with respect to theoretical models for simple colloids?

- Are the $(\phi, \Pi)$ diagrams that we obtain for lysozyme the experimental reference for true equations of state (EOS)?

\section{Materials and methods}

Sample preparation. Lysozyme hydrochloride powder (lysozyme purity higher than $98 \%$, as determined by reversed-phase high-performance liquid chromatography (HPLC)) was a gift from LIOT (Annezin, France). Stock solutions were prepared by solubilizing protein in $18 \mathrm{M} \Omega$ resistivity Milli-Q water (Merck Millipore, Darmstadt, Germany) and were kept at $4^{\circ} \mathrm{C}$.

Osmotic stress technique. The osmotic stress experiments were performed according to the procedure described by Bouchoux et al. ${ }^{20}$ The osmotic stress technique is based on osmosis: the disequilibrium of chemical potentials between the interior of the dialysis bag, containing the protein solution, and the surrounding medium of controlled osmotic pressure causes a water flow from the high to the low chemical potential compartments. When the high chemical potential side is the protein solution, the latter is concentrated until equilibrium is reached.

We used four types of bis-tris propane-HCl buffers: $\mathrm{pH} 7$ and $20 \mathrm{mM}$, $35 \mathrm{mM}$ and $150 \mathrm{mM}$ ionic strength, and $\mathrm{pH} 9$ and $20 \mathrm{mM}$ ionic strength. Lysozyme net charges of $+8.3 e$ and $+6.3 e$ at $\mathrm{pH} 7$ and $\mathrm{pH} 9$, respectively, were predicted from its three-dimensional structure (PDB ID: 2 VB1 ${ }^{36}$ ) using PROPKA ${ }^{37,38}$ (see also Fig. S1, ESI). Each buffer contained $0.2 \mathrm{~g} / \mathrm{L}$ thimerosal (Sigma, Saint Louis, USA) in order to avoid bacterial development. The bis-tris propane total concentration was chosen to account for an ionic strength of $20 \mathrm{mM}$, depending on the pH: $11.3 \mathrm{mM}$ at $\mathrm{pH} 7$ and $40 \mathrm{mM}$ at $\mathrm{pH}$ 9. Ionic strengths of $35 \mathrm{mM}$ and $150 \mathrm{mM}$ were obtained by adding $\mathrm{NaCl}$. Thimerosal, bis-tris 
propane (1,3-Bis[tris(hydroxymethyl)methylamino]propane) and $\mathrm{NaCl}$ were bought from Sigma-Aldrich (Saint-Louis, USA).

Polymer solutions were prepared directly in $500 \mathrm{~mL}$ glass bottles, by mixing the desired amount of polyethylene glycol (PEG) 20000 (SigmaAldrich, Saint-Louis, USA) and buffer at $20^{\circ} \mathrm{C}$. To relate PEG 20000 concentrations and osmotic pressures, we used the single-parameter phenomenological equation of state of PEG established by Cohen et al. ${ }^{39}$, assuming a prefactor $\alpha=0.44$, a monomer mass $M_{\mathrm{m}}=44 \mathrm{Da}$ and a specific partial volume $\bar{V}=0.825 \mathrm{~mL} / \mathrm{g}$ for PEG 20000 :

$$
\Pi N^{9 / 5}=\frac{R T}{M_{\mathrm{m}} \bar{V}}\left(\frac{C}{C_{\mathrm{N}}^{*}}+\alpha\left(\frac{C}{C_{\mathrm{N}}^{*}}\right)^{9 / 4}\right)
$$

where $N$ is the number of monomers per PEG molecule. The concentration $C_{\mathrm{N}}^{*}$ is defined by:

$$
C_{\mathrm{N}}^{*}=\frac{N^{-4 / 5}}{\bar{V}}
$$

Polymer solutions were kept at $20^{\circ} \mathrm{C}$ during the whole experiments.

We used a SpectraPor Dialysis Membrane, with a 6-8 kDa molecular mass cutoff and a $6.4 \mathrm{~mm}$ diameter (SpectrumLabs, Rancho Dominguez, USA) for the dialysis bags. Such a mass cutoff allows free exchange of ions and water, but not that of proteins and PEG 20000. For each bag, a $10 \mathrm{~cm}$ length of dialysis membrane was cut and rinsed in Milli Q water. The bag was then filled with a protein stock solution of low concentration $(50 \mathrm{~g} / \mathrm{L}$ for osmotic pressures higher than $0.39 \mathrm{bar}, 10 \mathrm{~g} / \mathrm{L}$ at pressures of 0.05 bar and 0.12 bar) and immersed in the polymer solution.

Due to the water efflux, the volume of the dialysis bags decreased. Dialysis bags were frequently taken out of the polymer solution, rinsed carefully with deionized water in order to avoid contamination of the protein solution with PEG 20000 , then opened and re-filled with the low-concentration protein solution. The already stressed, concentrated solution and the new, dilute one were then homogenized, and the bag was put back in the polymer solution.

As the rise in concentration of the solution inside the bags can be very important, especially for solutions subject to high osmotic pressures, the solutions subject to pressures higher than 1.16 bar were first equilibrated to $1.16 \mathrm{bar}$ for one week. The solutions subject to pressures lower than 1.16 bar were directly put to their final osmotic pressure. After one week, all the bags were transferred into new polymer solutions, of their final osmotic pressure. They were kept in these solutions for two weeks, during which they were frequently refilled, in order to obtain a weight of protein solution that was sufficient to make a dry content analysis (more than $1 \mathrm{~g}$ ). At the end of the 
two weeks, the bags were considered of sufficient volume and were no more re-filled. However, during the two weeks, some water flowed out of the bags and diluted the polymer solution, which decreased slightly the external osmotic pressure. Thus, the bags were finally transferred in new polymer solutions of the desired osmotic pressure, and kept without re-filling for one more week. At the end of these four weeks, the protein solution was considered to be in equilibrium with the surrounding polymer solution.

For decompression experiments, the protein solution was first equilibrated at the desired final osmotic pressure following the procedure described above. Then, the dialysis bag was put in a polymer solution of higher osmotic pressure for a week, without re-filling it. Finally, the bag was put back in a polymer solution inducing the same osmotic pressure as initially. In the following, we shall refer to this compressiondecompression cycle as "two-way compression".

Dry content measurement. This technique was used to determine the concentration of protein in the concentrated solutions obtained by osmotic pressure.

We used stainless steel cupels (diameter $60 \mathrm{~mm}$, height $25 \mathrm{~mm}$ ), with a removable lid. In each cupel, we put $25 \mathrm{~g}$ of Fontainebleau sand. The cupels and small glass rods were put in an oven at $102^{\circ} \mathrm{C}$ for $2 \mathrm{~h}$ minimum, with the lid open, in order to eliminate remaining water. The cupels and rods were then left to cool at room temperature in a dessicator containing recently dehydrated silica gel, under vacuum, for minimum $45 \mathrm{~min}$.

After cooling, each cupel was weighed (precision of $0.1 \mathrm{mg}$ ) with its lid closed and a glass rod. Each bag was rinsed, then opened and the protein solution was quickly put in a cupel. The total (cupel, lid, sample and glass rod) was then weighed. The sample was mixed with the Fontainebleau sand with the glass rod, which was left inside the cupel. The cupel (lid open) was then put in an oven at $102^{\circ} \mathrm{C}$ overnight.

The day after, each cupel with its glass rod (lid closed) was left to cool at room temperature in a dessicator containing recently dehydrated silica gel for minimum $45 \mathrm{~min}$. After cooling, each cupel was weighed (precision of $0.1 \mathrm{mg}$ ) with its lid closed.

Dry content weights were corrected for sodium chloride and bis-tris propane weights. Conversion from weights to volume fractions was performed considering that lysozyme had a specific partial volume of $0.712 \mathrm{~mL} / \mathrm{g}^{40}$.

Dynamic vapor sorption (DVS). Desorption isotherm of a $50 \mathrm{~g} / \mathrm{L}$ lysozyme solution was obtained with a dynamic vapor sorption analyzer DVS (Surface Measurement Systems Ltd., London, UK) equipped with 
a Cahn microbalance. The experiments were carried out at constant temperature $\left(20^{\circ} \mathrm{C}\right)$ and relative humidity values of $5 \%, 60 \%$ and $90 \%$, to reach water activity values of $0.05,0.6$ and 0.9 , respectively, at the equilibrium.

The water activity was converted to osmotic pressure using the formula:

$$
\Pi=-\frac{R T}{v_{\mathrm{a}}} \ln \left(a_{\mathrm{w}}\right)
$$

with $\Pi$ the osmotic pressure (in $\mathrm{Pa}$ ), $R$ the universal gas constant, $T$ the temperature, $v_{\mathrm{a}}$ the molar volume of water and $a_{\mathrm{w}}$ the water activity.

\section{Results}

\subsection{Osmotic pressure profiles of lysozyme in a $\mathrm{pH} \mathrm{7,}$ $I=20 \mathrm{mM}$ buffer}

Fig. 1 presents the measured values of the protein volume fraction (horizontal axis) according to the osmotic pressures applied to the solution of lysozyme in a buffer at $\mathrm{pH} 7$, and ionic strength $20 \mathrm{mM}$. In these conditions the net charge per protein is $+8.3 e$ (see Materials and methods). As a comparison, we plotted the van't Hoff law of ideal gases, $\Pi=\rho k_{\mathrm{B}} T$, where $\rho$ is the number density and $k_{\mathrm{B}}$ the Boltzmann constant, and the Carnahan-Starling $\operatorname{EOS}^{41}, \Pi=\rho k_{\mathrm{B}} T \frac{1+\phi+\phi^{2}-\phi^{3}}{(1-\phi)^{3}}$, where $\phi$ is the volume fraction, which describes a hard sphere gas ${ }^{15}$, using the lysozyme molecular weight $(14313 \mathrm{Da})^{42}$ and partial specific volume $(0.712 \mathrm{~mL} / \mathrm{g})^{40}$ so that the volume and mass of the equivalent spheres are equal to those of the proteins. The radius of the equivalent spheres is $1.59 \mathrm{~nm}$.

The data demonstrate that osmotic stress makes it possible to cover three decades in osmotic pressures and two decades in volume fractions. At very high pressures, our data for $\mathrm{pH} 7$ and ionic strength $35 \mathrm{mM}$ match the results obtained by Rickard et al. through single particle sorption ${ }^{29}$ and our own dynamic vapor sorption (DVS) results. It is noteworthy that, in contrast with osmotic stress, DVS and Rickard's microparticle technique concentrate all solutes, including salts, so that the ionic strength may vary.

The osmotic pressure profile can be divided into three parts: a dilute regime, up to $\phi=0.1$; a transition regime, ranging from $\phi=$ 0.1 to 0.5 , where the slope of the curve decreases until a plateau, characterized experimentally by a large step in volume fraction (almost two-fold increase); then a concentrated regime, above $\phi=0.5$, where the pressure increases steeply with volume fraction. 


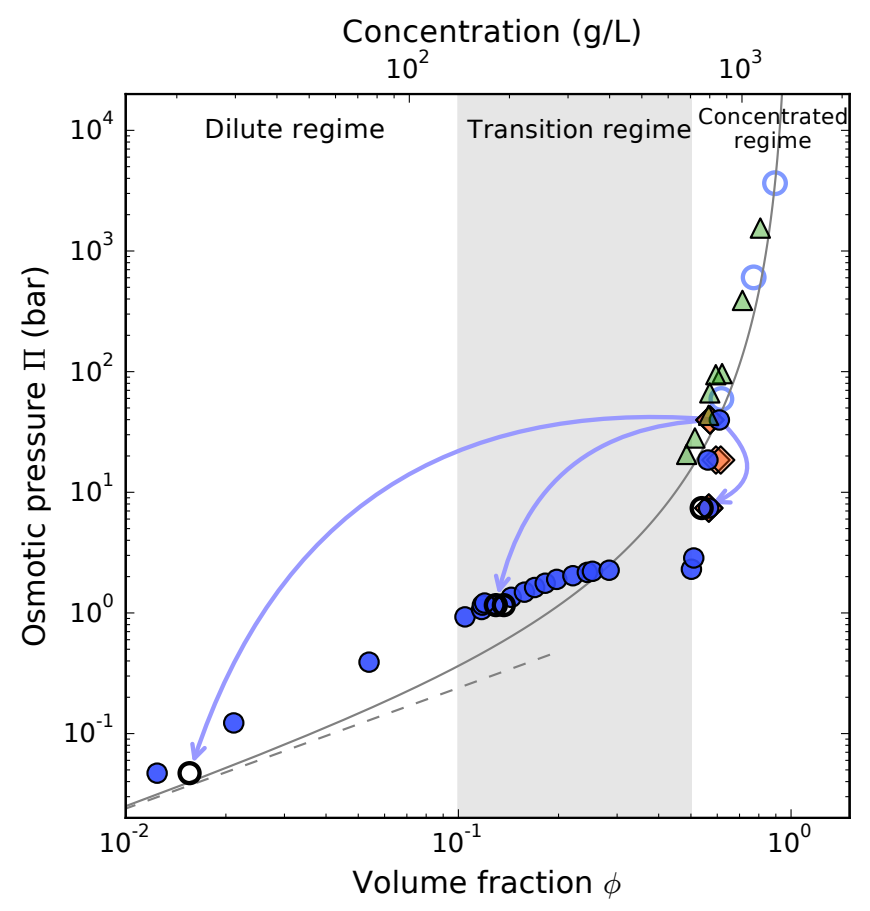

Figure 1: $(\phi, \Pi)$ diagram of lysozyme in a $\mathrm{pH} 7, I=20 \mathrm{mM}$ bis-tris propane buffer, obtained by one-way compression (filled blue circles), or by compression to 39.75 bar followed by decompression to different pressures ("two-way compression", empty black circles): the arrows symbolize the decompression part of the two-way compression experiments. The solid line represents the Carnahan-Starling model, the dashed black line represents the van't Hoff model. Data from Rickard et al. ${ }^{29}$ obtained by bulk vapor desorption are represented by green triangles. Our data from dynamic vapor sorption (DVS, empty blue circles) were obtained using lysozyme solutions initially at $\mathrm{pH} 7$ and $35 \mathrm{mM}$ ionic strength, but DVS does not keep concentrations constant. Crystal densities extracted from SAXS data (see discussion, section 4.2) are represented by orange diamonds.

The use of the van't Hoff and Carnahan-Starling models is generally restricted to fluid, dilute systems ${ }^{43}$. In our case, in the dilute regime, the pressures of the lysozyme solutions are approximately twice as large as the Carnahan-Starling model or a van't Hoff perfect gas system. In the discussion, section 4 , we shall present a model that explains the origin of this excess pressure. 


\subsection{Morphology of lysozyme solutions in a pH 7, $I=$ $20 \mathrm{mM}$ buffer}

The pictures shown in Fig. 2 have been chosen to illustrate the changes in morphology of the lysozyme solution ( $\mathrm{pH} \mathrm{7,} I=20 \mathrm{mM}$ buffer) submitted to different osmotic pressures.

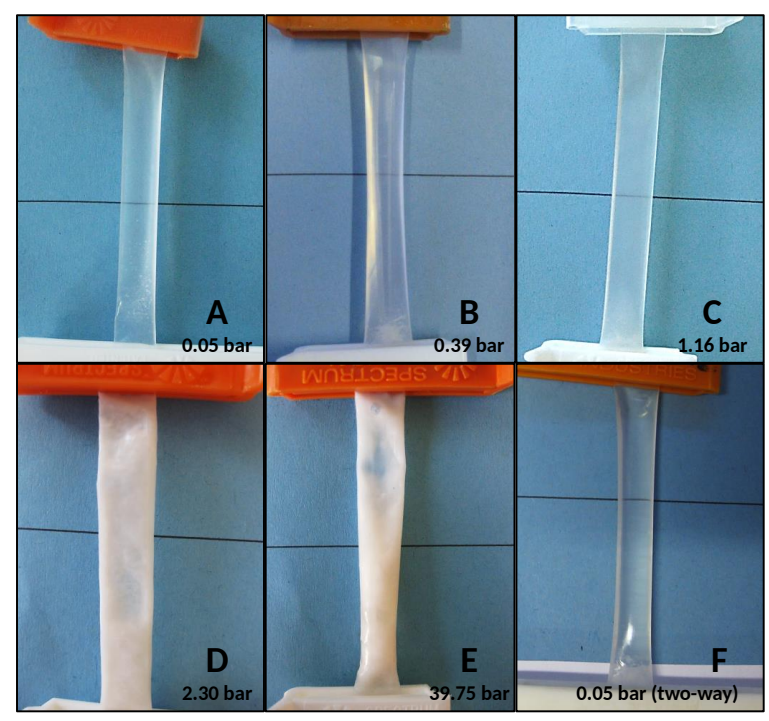

Figure 2: Photographs of dialysis bags containing lysozyme at $\mathrm{pH} 7$ and $20 \mathrm{mM}$ ionic strength, submitted to different osmotic pressures: 0.05 bar (A), 0.39 bar (B), 1.16 bar (C), 2.30 bar (D) and 39.75 bar (E). Photograph (F) shows the bag after compressing the solution from 0.05 bar to 39.75 bar, then decompressing it back to 0.05 bar.

The $10 \mathrm{~g} / \mathrm{L}$ and $50 \mathrm{~g} / \mathrm{L}(\phi=0.0071$ and 0.0356 , respectively) stock solutions are clear, transparent liquids that flow easily. Samples obtained by osmotic compression have the same aspect as the stock solutions from 0.05 bar (Fig. 2A) to 0.12 bar. When the solutions are concentrated further, they become increasingly dense but remain transparent, with some white, fluffy aggregates visible at the bottom of the bag (Fig. 2B and 2C). For pressures above 2.26 bar, namely above the "large volume fraction step" (see section 3.1), the samples become white and solid (Fig. 2D and 2E). If a sample is compressed to 0.05 bar, then 39.75 bar, and finally de-compressed to 0.05 bar without any mechanical treatment, the solid re-dissolves spontaneously and completely, and becomes as clear and liquid as the original sample compressed at 0.05 bar, without any insoluble part remaining (Fig. 2F). This morphological reversibility needs to be confirmed from a thermodynamic point 
of view, as addressed in the following section.

\subsection{Thermodynamic reversibility of the compression}

We designed several experiments in order to verify that the same points on the osmotic pressure profile can be attained through different paths.

We performed osmotic compressions at 0.05 bar, 1.16 bar and 7.40 bar at $\mathrm{pH} 7$ and $I=20 \mathrm{mM}$. After equilibrium was reached, we immersed the dialysis bags in a PEG solution at a 39.75 bar osmotic pressure. After a new equilibrium, we brought each bag back to its initial osmotic pressure ("two-way compression").

As shown on Fig. 1, for 3 cycles with different final osmotic pressures, we found that the final volume fractions were similar for samples obtained through one-way compression and through two-way compression.

We performed additional experiments at $\mathrm{pH} 7, I=35 \mathrm{mM}$ and $\mathrm{pH}$ 7, $I=150 \mathrm{mM}$ (see Fig. S2 and S3, ESI), and we also changed the pathways of the cycles: for $\mathrm{pH} 7$ and $I=35 \mathrm{mM}$ (Fig. S3, ESI), each sample was compressed to a different osmotic pressure and were then decompressed to the same osmotic pressure $(0.57 \mathrm{bar})$. The results confirm that, on both sides of the "large volume fraction step", one-way and two-way compressions are equivalent.

\subsection{Influence of $\mathrm{pH}$ and ionic strength}

In another set of osmotic stress experiments, we reduced the net charge of the protein to $Z=+6.3 e$ (see Materials and methods) by using a $\mathrm{pH} 9, I=20 \mathrm{mM}$ bis-tris propane buffer. Alternatively, we kept $\mathrm{pH}$ at 7 but adjusted the ionic strength to $35 \mathrm{mM}$ and $150 \mathrm{mM}$ by adding $\mathrm{NaCl}$. Fig. 3 presents the $(\phi, \Pi)$ diagrams obtained for each condition, compared with the $(\phi, \Pi)$ diagram obtained at $\mathrm{pH} 7, I=20 \mathrm{mM}$.

Increasing $\mathrm{pH}$ at constant ionic strength or increasing the ionic strength at constant $\mathrm{pH}$ causes a shift of the experimental curve towards lower osmotic pressures in the dilute and the transition regimes. However, in the concentrated regime, the volume fraction is the same for all the conditions. Whatever $\mathrm{pH}$ and ionic strength, the evolution of the solutions morphology follows the same pattern as for $\mathrm{pH} 7$, $I=20 \mathrm{mM}$, showing in particular solidification for concentrations above the "large volume fraction step".

\section{Discussion}

The results presented above demonstrate that the use of osmotic stress applied through a dialysis equilibrium makes it possible to cover a vol- 


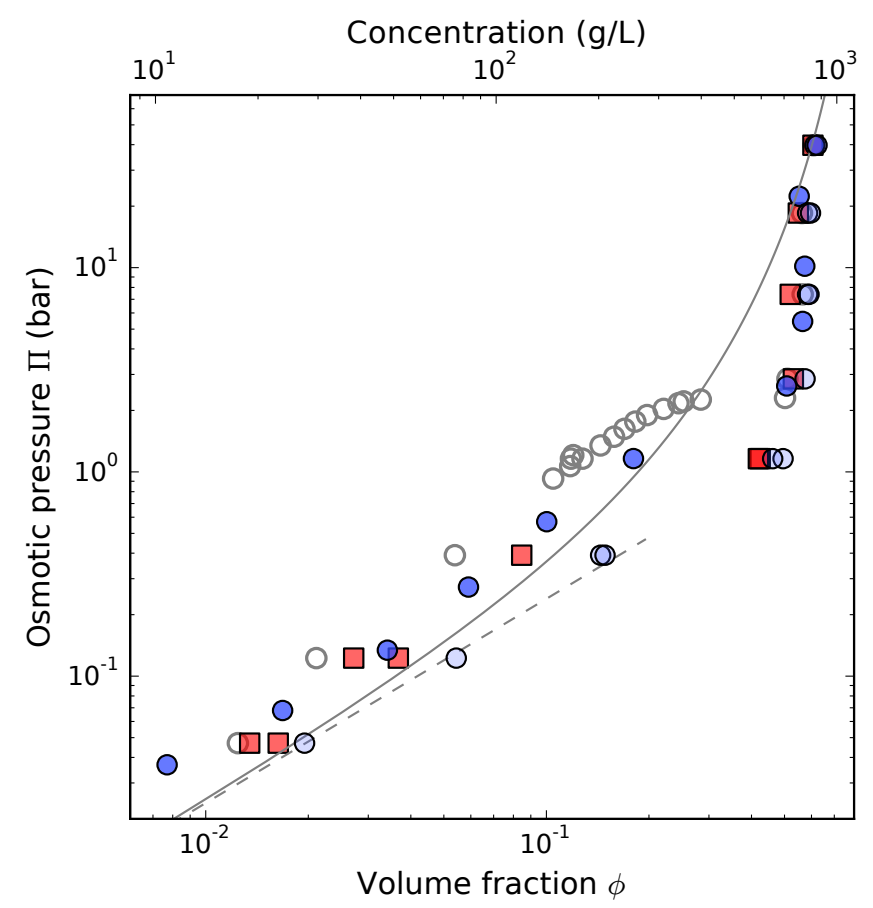

Figure 3: $(\phi, \Pi)$ diagrams of lysozyme for several physicochemical conditions. Conditions presented are: $\mathrm{pH} 7$, ionic strength $I=20 \mathrm{mM}$ (grey empty circles); $\mathrm{pH} 7, I=35 \mathrm{mM}$ (dark blue circles); $\mathrm{pH} 7, I=150 \mathrm{mM}$ (light blue circles) and $\mathrm{pH} 9, I=20 \mathrm{mM}$ (red squares). The solid line represents the CarnahanStarling model, the dashed line represents the van't Hoff model.

ume fraction / osmotic pressure range that joins, at high concentrations, the data obtained through vapor sorption ${ }^{29}$ (Fig. 1). The lowest concentrations that we have studied match the lysozyme concentration in egg white and the highest ones reach those commonly met in industrial processes.

The first aim of this section is to show that the reported $(\phi, \Pi)$ diagrams, unambiguously relating the volume fraction to the osmotic pressure of lysozyme solutions at chosen ionic conditions, constitute the reference experimental counterpart of equations of state (EOS) for lysozyme solutions. We shall then address the nature of the transition regime and its relationship to the volume fractions of the concentrated regime, by considering the nature of the interactions between solutes in the ionic conditions that are imposed by the outer stressing solution. 


\subsection{The $(\phi, \Pi)$ diagrams are reference experimental data for equations of state}

The first argument comes from the thermodynamic reversibility of the transformations of the system. Preliminary observations of the morphology gave us a clue about this reversibility, as the samples get back to their liquid, clear form when decompressed to low osmotic pressures, even after having been strongly compressed at 39.75 bar. Focusing on the $(\phi, \Pi)$ diagrams reveals that compressing a lysozyme solution to 39.75 bar and decompressing it back to a lower pressure is equivalent to a one-way compression to the lowest pressure, for ionic strengths ranging from $20 \mathrm{mM}$ to $150 \mathrm{mM}$ at $\mathrm{pH} 7$. The analysis of the $\mathrm{pH} 7$, $I=20 \mathrm{mM}$ samples by Fourier transform infrared spectroscopy (FTIR) clearly showed that the system was composed of the same structural entities, regardless of the volume fraction or the pathway (Fig. S4, ESI). All these features proved that the state of the solution reversibly depends on the pressure, volume fraction and physicochemical conditions, and not on the compression history.

Considering the above, in addition to the fact that the diagrams originate from several data sets and batches of protein, we can state that we established the reference experimental data for equations of state (EOS) of lysozyme solutions, for ionic strengths up to $150 \mathrm{mM}$.

\subsection{Nature of the transition regime}

Since our data points identify equilibrium states of the system, the existence of a plateau, where the chemical potential of water remains nearly constant over a large range of volume fraction, must reflect the existence of a phase transition.

Small angle X-ray scattering (SAXS) data obtained in the concentrated regime reveal lysozyme crystallization, as shown by Bragg peaks, in all ionic conditions up to $I=150 \mathrm{mM}$. As an example, the structure factors of lysozyme solutions in a $\mathrm{pH} 7, I=20 \mathrm{mM}$ buffer compressed at 1.16 bar and 39.75 bar are presented on Fig. S5, ESI. We therefore propose that the phase transition evidenced by the $(\phi, \Pi)$ diagrams is caused by crystallization of the protein. This hypothesis is consistent with the solubilities determined by Retailleau et al. ${ }^{44}$ for lysozyme at pH 6.5 and different $\mathrm{NaCl}$ concentrations $(\phi=0.25,0.15$ and 0.10 for $0 \mathrm{mM}, 50 \mathrm{mM}$ and $100 \mathrm{mM} \mathrm{NaCl}$, respectively).

We interpret the SAXS spectra as powder diffraction spectra. The major crystalline form is tetragonal, of the $\mathrm{P} 4_{3} 2_{1} 2$ space group, as found in numerous crystallographic structures of lysozyme (see e.g., $1 \mathrm{HEL}^{45}$ ). Fitting the lattice parameters allows us to estimate the volume fraction of protein in the crystal. As shown in Fig. 1, the values that result from the fit are quite consistent with the volume fractions of the 
samples in concentrated regime, indicating that all of the lysozyme was crystallized in these samples. The volume fraction variations between the points shown on the diagram are related to slight changes in the $\mathrm{P}_{3} 2_{1} 2$ lattice parameters.

Rickard et al. ${ }^{29}$ found higher osmotic pressures at volume fraction $\phi=0.52$ and did not mention crystallization. This is easily explained by the kinetics of concentration in that case. Indeed, the dehydration method used by Rickard et al. causes a rapid concentration of the lysozyme solution, leading to a glassy state within the compressed droplets. Therefore the crystals do not nucleate, and the $(\phi, \Pi)$ diagram follows a liquid-like tendency, parallel to the Carnahan-Starling model, instead of following the bend caused by crystallization in our slow equilibrium experiments. The ratio of osmotic pressures of the glassy and crystal states $(\times 10)$ is comparable with the solubility ratios commonly found for amorphous and crystalline solids.

The question then arises of the smoothness of the change of slope at the beginning of the transition regime. Indeed, as soon as the nuclei of the crystal have reached the critical size, crystallization should occur without any barrier. Therefore the concentration in the liquid protein phase would remain constant as the chemical potential of lysozyme must be the same in the liquid and crystallized phases. Accordingly, the data would then show an angular profile at the leading edge of the plateau, instead of the smooth pretransition bending shown in Figs. 1 and 3.

The existence of an intermediate regime of sub-critical nuclei, or equilibrium clusters ${ }^{24,25}$, could explain the pre-transition bending, as the concentration range where the equilibrium clusters have been observed $(\phi=0.12-0.23)$ is consistent with most of the transition regime of the $(\phi, \Pi)$ diagram, and the conditions are quite close to ours ${ }^{25}$ : low ionic strength, $\mathrm{pH} 7.8$ instead of 7 , and same temperature $25^{\circ} \mathrm{C}$ ). In the next section, we will however show that the pre-transitional bending can also be explained quantitatively by the effects of ionic screening and van der Waals forces.

\subsection{Interactions between proteins}

Since the structure of lysozyme molecules remains the same through the whole range of pressures and volume fractions, it becomes interesting to compare the osmotic pressures of their solutions with those from dispersions of monodisperse spherical particles. A first observation is that the Carnahan-Starling equation of state provides a surprisingly good fit to the data over 4 decades in pressures, and even at concentrations where the virial equation of state with only 2-body interactions is not expected to hold (Fig. 1). Here we show that deviations from the Carnahan-Starling equation can be partly accounted for by taking into 
account the ionic interactions between proteins, and their interactions due to van der Waals forces.

To explain the impact of ionic conditions on osmotic pressures in the dilute regime, with the simple hypotheses that lysozyme molecules are spheres with a uniform surface charge density and following a meanfield approach, we developed a generalized van der Waals (GVDW) model (see the full development in Supporting Information) leading to the expression of the osmotic pressure as a function of an effective pair potential:

$$
\beta \Pi \frac{v}{\phi}=\frac{1+\phi+\phi^{2}-\phi^{3}}{(1-\phi)^{3}}+2 \pi \frac{\phi}{v} \int_{2 a}^{\infty} \beta w(r) r^{2} \mathrm{~d} r
$$

where $\beta=1 / k_{\mathrm{B}} T$ is the reciprocal of the thermal energy, $\Pi$ is the osmotic pressure, $v$ is the protein molecular volume, $\phi$ is the volume fraction, $a$ is the molecular hard-core radius, $r$ the intermolecular centerto-center distance and $w$ is an effective pair potential.

In order to account for the shift of the experimental osmotic pressures upon changes in $\mathrm{pH}$ or ionic strength, we describe the contribution of screened ionic repulsions to the pair potential by a Debye-Hückel potential,

$$
\beta w_{\mathrm{DH}}(r)=\frac{Z^{2} L_{\mathrm{B}}}{(1+\kappa a)^{2}} \frac{\mathrm{e}^{-\kappa(r-2 a)}}{r}
$$

where $Z$ is the molecular charge, $L_{\mathrm{B}}$ is the Bjerrum length. $\kappa$ is the reciprocal of the screening length and, if the protein counterions are taken into account, $\kappa$ is defined by:

$$
\kappa^{2}=4 \pi L_{\mathrm{B}} N_{\mathrm{A}}\left(2 C_{\mathrm{S}}+Z C_{\mathrm{P}}\right)
$$

where $N_{\mathrm{A}}$ is the Avogadro constant, $C_{\mathrm{S}}$ is the pair concentration of monovalent salt and $C_{\mathrm{P}}$ is the protein molar concentration.

The contribution of short-ranged van der Waals forces to the effective pair potential is accounted for by a Hamaker potential,

$$
\beta w_{\mathrm{H}}(r)=-\frac{A_{\mathrm{H}}}{6}\left(\frac{2 a^{2}}{r^{2}-4 a^{2}}+\frac{2 a^{2}}{r^{2}}+\ln \left(\frac{r^{2}-4 a^{2}}{r^{2}}\right)\right)
$$

for $r>2 a$, infinity otherwise, where $A_{\mathrm{H}}$ is the Hamaker constant (in $k_{\mathrm{B}} T$ units).

The total pair potential can be written as $w(r)=w_{\mathrm{DH}}(r)+w_{\mathrm{H}}(r)$, and the expression of osmotic pressure given by Eq. 4 then can be fitted to the experimental data, through numerical integration of its interaction term, using the Hamaker constant $A_{\mathrm{H}}$ as the only adjustable parameter (the lower integration limit was increased by $0.02 \mathrm{~nm}$ to avoid divergence). 
We fit this model in the packing fraction region below the crystallization, with a global $A_{\mathrm{H}}$, common to all $\mathrm{pH}$ and ionic strength conditions. The protein charge $Z$ was fixed to the theoretical net charge of the protein for the considered $\mathrm{pH}$. Results are shown in Fig. 4, where the model is drawn on the experimental points used for the fitting.

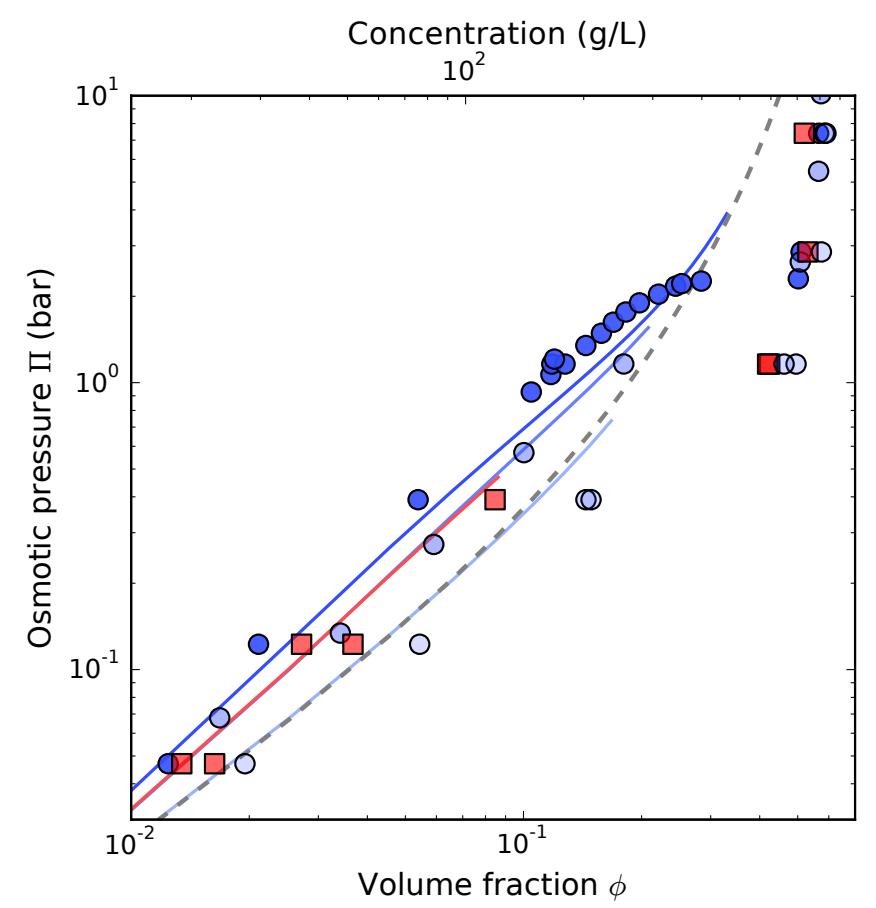

Figure 4: Fit of the generalized van der Waals model to the experimental osmotic pressures of lysozyme in the dilute region. The model (solid lines) was fitted simultaneously to the 4 plotted series of experimental data, using $Z / e$ values of 8.3 and 6.3 at $\mathrm{pH} 7$ (circles) and $\mathrm{pH} 9$ (squares), respectively. The corresponding fitted value of the Hamaker constant is $3.76 k_{\mathrm{B}} T$. Conditions are $\mathrm{pH} 7, I=20 \mathrm{mM}$ (dark blue), $\mathrm{pH} 7, I=35 \mathrm{mM}$ (medium blue), $\mathrm{pH} 7, I=150 \mathrm{mM}$ (light blue) and $\mathrm{pH} 9, I=20 \mathrm{mM}$ (red). The model lines are plotted only in the volume fraction range used for the fit. The dashed line represents the Carnahan-Starling model.

In spite of large approximations (lysozyme figured as a spherical molecule with uniform surface charge density, mean-field model assuming a step-shaped pair correlation function), our single-parameter GVDW model accounts strikingly well for the shape of the experimental 
data in the low-concentration range, as well as for their tendency to shift upon changes in the ionic conditions.

As regards the shape of the $(\phi, \Pi)$ diagrams, especially the downward bending observed below the crystallization plateau, it is important to point out that the counterions of the proteins strongly screen the electrostatic interactions, especially at high protein volume fractions, and that it is necessary to take this contribution into account in order to reproduce the shape of the data in the dilute and transition regime (see Fig. S6, ESI, for an example at pH 7 and ionic strength $20 \mathrm{mM}$ ). The increase of the concentration of these counterions, and thus of the effective ionic strength, with volume fraction may be a cause of the existence of equilibrium clusters in a concentration range that is consistent with the transition regime of the $(\phi, \Pi)$ curve. Indeed, the bending of the curve occurs when the counterions concentration is sufficient to decrease significantly the repulsions between proteins and thus favor the attractions, giving rise to a new balance of interactions. Moreover, the aggregation number of the equilibrium clusters has been shown to be related to changes that favor attractions over repulsions, such as a decrease of the temperature or an increase of the salt concentration, but also to the increase in volume fraction ${ }^{24,25}$. This latter point could be explained by the increase in counterion concentration, which has a major effect in screening ionic repulsions, as explained above. This screening of ionic repulsions may cause an increase in the size of equilibrium clusters size, until the repulsions are so low that a barrier no longer exists to lysozyme self-association. At this point the association of lysozyme into equilibrium clusters is preempted by crystallization.

The fitted model still fails to describe quantitatively the strength of ionic repulsions at low ionic strength, and also the strength of attractions at high ionic strength.

The discrepancy between the experimental data and the model could be due to the simplicity of the assumptions of our model (uniformly charged spherical particles). It could also be due to specific interactions of salt ions with protein residues, which are the subject of a very active debate ${ }^{46-50}$. In particular, deviations of the effective net charge from the predicted one may be caused by added salt due to ionic strength effects but also to specific ion effects ${ }^{51-53}$.

\section{Conclusion}

Our results show complete experimental osmotic pressures $v s$. volume fraction for the aqueous solutions of a protein. Each point of these curves illustrates an equilibrium state of the lysozyme solution. Relationships between osmotic pressure and concentration in solu- 
tions of lysozyme and a few other proteins have already been described $^{11-14,20,54,55}$, but our experiments span much wider ranges of osmotic pressure and concentration. As a consequence, all the states classically described for protein solutions have been explored, from the ideally dilute solution to the solid state, for which the solidus line, usually extrapolated from the density of crystals, is poorly described in phase diagrams ${ }^{56}$. Moreover, these data highlight the crystallization transition, and its displacement towards lower volume fractions caused by the decrease of the range and strength of the electrostatic interactions. The crystallization transition shown by our data is consistent with the solubility data available in the literature ${ }^{44}$, and with a crystal space group well known for lysozyme ${ }^{45}$.

Simple colloidal models, without interactions other than steric, such as the Carnahan-Starling model, do not reproduce any of our data series. However, for all our experimental data, the low packing fraction region up to the crystallization event is correctly described by the combination of a steric repulsion (Carnahan-Starling model), van der Waals forces and a screened electrostatic repulsion as described by the classical Debye-Hückel potential, provided that the contribution from the counterions of the proteins to the screening is taken into account. Quantitative agreement between this model and the experimental data would probably require to take into account the shape and charge distribution of the molecules. The possible specific interactions between ions and protein residues ${ }^{51,57-59}$ could also make the electrical charge of the protein deviate from theoretical predictions based of the $\mathrm{p} K_{\mathrm{a}}$ of the aminoacids.

The mechanisms involved in our description of the dilute part of the osmotic pressure $v s$. volume fraction of lysozyme, i.e., the balance between short-range attraction and long-range repulsion have been described for colloids ${ }^{60}$ and lysozyme ${ }^{24}$ and may be applicable to other proteins. However, some features of our experimental data are related to specific properties of lysozyme, like its ability to crystallize in the physicochemical conditions we used. Indeed, the plateau reflecting the crystallization transition has not yet been observed for other globular proteins, such as ovalbumin ${ }^{12}$ or BSA $^{11}$. This may be due to the smaller range of concentration, but more likely to the experimental conditions $(\mathrm{pH}$, ionic strength, nature of salts, kinetics of concentration, temperature) that, depending on the protein, favor behaviors other than crystallization when the solutions are highly concentrated. The high concentration part of the osmotic pressure $v s$. volume fraction curve is then probably also controlled by other protein properties, such as anisotropy of shape and charge density. The determination of the contribution of these structural specificities in the equations of state of proteins is still to be explored. 


\section{Acknowledgement}

The authors thank Martine Meireles, Yannick Hallez, Christophe Labbez, Marie Skepö, Valérie Briard-Bion, Julien Jardin for helpful discussions.

\section{References}

[1] A. D. Marshall, P. A. Munro and G. Trägårdh, Desalination, 1993, 91, 65-108.

[2] M. E. M. Cromwell, E. Hilario and F. Jacobson, AAPS J., 2006, 8, E572-E579.

[3] P. Ball, Nat. Mater., 2012, 11, 185.

[4] A. U. Borwankar, A. K. Dinin, J. R. Laber, A. Twu, B. K. Wilson, J. A. Maynard, T. M. Truskett and K. P. Johnston, Soft Matter, 2013, 9, 1766.

[5] K. P. Johnston, J. A. Maynard, T. M. Truskett, A. U. Borwankar, M. A. Miller, B. K. Wilson, A. K. Dinin, T. A. Khan and K. J. Kaczorowski, ACS Nano, 2012, 6, 1357-1369.

[6] R. J. Ellis and A. P. Minton, Nature, 2003, 425, 27-28.

[7] A. Saluja and D. S. Kalonia, Int. J. Pharm., 2008, 358, 1-15.

[8] F. Carlsson, M. Malmsten and P. Linse, J. Phys. Chem. B, 2001, 105, 12189-12195.

[9] F. Cardinaux, E. Zaccarelli, A. Stradner, S. Bucciarelli, B. Farago, S. U. Egelhaaf, F. Sciortino and P. Schurtenberger, J. Phys. Chem. B, 2011, 115, 7227-7237.

[10] C. Gögelein, G. Nägele, R. Tuinier, T. Gibaud, A. Stradner and P. Schurtenberger, J. Chem. Phys., 2008, 129, 085102.

[11] V. L. Vilker, C. K. Colton and K. A. Smith, J. Colloid Interface Sci., 1981, 79, 548-566.

[12] M. A. Yousef, R. Datta and V. G. J. Rodgers, J. Colloid Interface Sci., 2001, 243, 321-325.

[13] Y. U. Moon, C. O. Anderson, H. W. Blanch and J. M. Prausnitz, Fluid Phase Equilib., 2000, 168, 229-239.

[14] Y. U. Moon, R. A. Curtis, C. O. Anderson, H. W. Blanch and J. M. Prausnitz, J. Solution Chem., 2000, 29, 699-718. 
[15] C. Bonnet-Gonnet, L. Belloni and B. Cabane, Langmuir, 1994, 10, 4012-4021.

[16] A. S. Robbes, F. Cousin and G. Meriguet, Braz. J. Phys., 2009, 39, 156-162.

[17] C. Martin, F. Pignon, A. Magnin, M. Meireles, V. Lelièvre, P. Lindner and B. Cabane, Langmuir, 2006, 22, 4065-4075.

[18] A. Mourchid, A. Delville, J. Lambard, E. Lécolier and P. Levitz, Langmuir, 1995, 11, 1942-1950.

[19] C. Vauthier, B. Cabane and D. Labarre, Eur. J. Pharm. Biopharm., 2008, 69, 466-475.

[20] A. Bouchoux, G. Gésan-Guiziou, J. Pérez and B. Cabane, Biophys. J., 2010, 99, 3754-3762.

[21] A. Bouchoux, P.-E. Cayemitte, J. Jardin, G. Gésan-Guiziou and B. Cabane, Biophys. J., 2009, 96, 693-706.

[22] R. Parker, T. R. Noel, G. J. Brownsey, K. Laos and S. G. Ring, Biophys. J., 2005, 89, 1227-1236.

[23] G. J. Brownsey, T. R. Noel, R. Parker and S. G. Ring, Biophys. J., 2003, 85, 3943-3950.

[24] A. Stradner, H. Sedgwick, F. Cardinaux, W. C. K. Poon, S. U. Egelhaaf and P. Schurtenberger, Nature, 2004, 432, 492-495.

[25] A. Stradner, F. Cardinaux and P. Schurtenberger, J. Phys. Chem. B, 2006, 110, 21222-21231.

[26] A. Shukla, E. Mylonas, E. D. Cola, S. Finet, P. Timmins, T. Narayanan and D. I. Svergun, Proc. Nat. Acad. Sci. U. S. A., 2008, 105, 5075-5080.

[27] P. Kowalczyk, A. Ciach, P. Gauden and A. Terzyk, J. Colloid Interface Sci., 2011, 363, 579-584.

[28] Y. Liu, L. Porcar, J. Chen, W.-R. Chen, P. Falus, A. Faraone, E. Fratini, K. Hong and P. Baglioni, J. Phys. Chem. B, 2011, 115, 7238-7247.

[29] D. L. Rickard, P. B. Duncan and D. Needham, Biophys. J., 2010, 98, 1075-1084.

[30] O. D. Velev, E. W. Kaler and A. M. Lenhoff, Biophys. J., 1998, 75, 2682-2697. 
[31] A. C. Dumetz, A. M. Chockla, E. W. Kaler and A. M. Lenhoff, Biophys. J., 2008, 94, 570-583.

[32] D. F. Rosenbaum and C. F. Zukoski, J. Cryst. Growth, 1996, 169, 752-758.

[33] E. J. Park and Y. C. Bae, Biophys. Chem., 2004, 109, 169-188.

[34] S. P. Rozhkov and A. S. Goryunov, Biophys. Chem., 2012, 170, 34-41.

[35] M. Muschol and F. Rosenberger, J. Chem. Phys., 1997, 107, 1953.

[36] J. Wang, M. Dauter, R. Alkire, A. Joachimiak and Z. Dauter, Acta Crystallogr., Sect. D, 2007, 63, 1254-1268.

[37] H. Li, A. D. Robertson and J. H. Jensen, Proteins: Struct., Funct., Bioinf., 2005, 61, 704-721.

[38] M. H. M. Olsson, C. R. Søndergaard, M. Rostkowski and J. H. Jensen, J. Chem. Theory Comput., 2011, 7, 525-537.

[39] J. A. Cohen, R. Podgornik, P. L. Hansen and V. A. Parsegian, J. Phys. Chem. B, 2009, 113, 3709-3714.

[40] V. A. Sirotkin, I. A. Komissarov and A. V. Khadiullina, J. Phys. Chem. B, 2012, 116, 4098-4105.

[41] N. F. Carnahan and K. E. Starling, J. Chem. Phys., 1969, 51, 635-636.

[42] A. Humeny, T. Kislinger, C.-M. Becker and M. Pischetsrieder, J. Agric. Food Chem., 2002, 50, 2153-2160.

[43] P. Richard, L. Oger, J.-P. Troadec and A. Gervois, Phys. Rev. E, 1999, 60, 4551-4558.

[44] P. Retailleau, M. Riès-Kautt and A. Ducruix, Biophys. J., 1997, 73, 2156-2163.

[45] K. P. Wilson, B. A. Malcolm and B. W. Matthews, J. Biol. Chem., 1992, 267, 10842-10849.

[46] P. Jungwirth, J. Phys. Chem. Lett., 2013, 4, 4258-4259.

[47] K. B. Rembert, J. Paterová, J. Heyda, C. Hilty, P. Jungwirth and P. S. Cremer, J. Am. Chem. Soc., 2012, 134, 10039-10046. 
[48] J. Paterová, K. B. Rembert, J. Heyda, Y. Kurra, H. I. Okur, W. R. Liu, C. Hilty, P. S. Cremer and P. Jungwirth, J. Phys. Chem. B, 2013, 117, 8150-8158.

[49] H. I. Okur, J. Kherb and P. S. Cremer, J. Am. Chem. Soc., 2013, 135, 5062-5067.

[50] W. J. Xie and Y. Q. Gao, J. Phys. Chem. Lett., 2013, 4, 4247-4252.

[51] A. Kurut and M. Lund, Faraday Discuss., 2013, 160, 271-278.

[52] M. Boström, D. R. M. Williams and B. W. Ninham, Biophys. J., 2003, 85, 686-694.

[53] C. A. Haynes, E. Sliwinsky and W. Norde, J. Colloid. Interf. Sci., 1994, 164, 394-409.

[54] C. A. Haynes, K. Tamura, H. R. Korfer, H. W. Blanch and J. M. Prausnitz, J. Phys. Chem., 1992, 96, 905-912.

[55] D. Farrer and A. Lips, Int. Dairy J., 1999, 9, 281-286.

[56] P. G. Vekilov, Soft Matter, 2010, 6, 5254-5272.

[57] M. Boström, F. W. Tavares, S. Finet, F. Skouri-Panet, A. Tardieu and B. W. Ninham, Biophys. Chem., 2005, 117, 217-224.

[58] Y. Zhang and P. S. Cremer, Proc. Nat. Acad. Sci. U. S. A., 2009, 106, 15249-15253.

[59] J. Zhang, Protein-Protein Interactions - Computational and Experimental Tools, InTech, 2012, pp. 359-376.

[60] J. Groenewold and W. K. Kegel, J. Phys. Chem. B, 2001, 105, 11702-11709. 